\title{
EDUCAÇÃO ESPECIAL NA INTERNET: BLOGS COMO RECURSOS DE FORMAÇÃO (INFORMAL) DE PROFESSORES
}

\section{SPECIAL EDUCATION ON THE INTERNET: BLOGS AS RESOURCES OF (INFORMAL) TEACHER TRAINING}

\section{EDUCACIÓN ESPECIAL EN LA INTERNET: USO DE BLOGS CÓMO RECURSO DE FORMACIÓN DE FORMACIÓN (INFORMAL) DEL PROFESOR}

\author{
Gabriela Alias Rios* \\ Enicéia Gonçalves Mendes*
}

\section{RESUMO}

No contexto da sociedade atual, as tecnologias estão cada vez mais presentes na vida cotidiana das pessoas, resultando numa mudança na velocidade da transmissão das informações, na maneira em como se dá a comunicação, interação entre as pessoas, e também na formação de profissionais. Nesse panorama, inserem-se os blogs, que são uma espécie de diário online utilizado para comunicação e interação entre as pessoas de diversas faixas etárias, interesses e profissões. A partir de buscas na internet, constata-se que os blogs são muito utilizados por professores. Nesta perspectiva, este trabalho teve como objetivos analisar e descrever o que professores divulgam em seus blogs sobre a Educação Especial, e se tais conteúdos se relacionam à formação destes profissionais. Para isso, buscas foram realizadas em site de busca a partir do descritor "educação especial". Como amostra, foram selecionadas dez páginas, tanto brasileiras quanto portuguesas. Foi traçado um perfil do professorblogueiro e analisados os conteúdos das postagens. Pode-se concluir que os professores-blogueiros têm, de alguma forma, relação com a Educação Especial. As postagens puderam ser categorizadas em quatro eixos e, após análise, constata-se que os blogs são um espaço que contribuem diretamente para a formação destes professores.

Descritores: Blogs, Educação Especial, Formação de professores.

\footnotetext{
* Graduada em Letras e Mestranda em Educação Especial. Programa de Pós-Graduação em Educação Especial, Universidade Federal de São Carlos - UFSCar. bihalias@ gmail.com. (16) 3351-9358

* Professora doutora do Programa de Pós-Graduação em Educação Especial, egmendes@ ufscar.b. egmendes@ ufscar.br (16) $3351-9358$
} 


\section{ABSTRACT}

Nowadays, technologies are increasingly present in people's daily lives, resulting in a change in the speed of transmission of information, in the way the communication happens, interaction among people, and also in professional training. In this context, we can highlight the blogs, which are a kind of online diary used for communication and interaction among people of different ages, interests and professions. From internet searches, it is noticed that blogs are often used by teachers. In this perspective, this study aimed to analyze and describe what teachers publish in their blogs about Special Education, and if these contents are related to the training of these professionals. For this, searches were conducted from a search website, by using the descriptor "special education." As a sample, we selected ten pages, Brazilian and Portuguese ones. It was drawn a profile of teacher-blogger and analyzed the contents of the postings. It can be concluded that teachers-bloggers have, in some way, relation to Special Education. The posts could be categorized into four areas and, after analysis; it was possible to conclude that blogs are a space that contribute directly to the formation of these teachers.

Keywords: Blogs, Special Education, Teacher Training.

\section{RESUMEN}

En el contexto de la sociedad actual, las tecnologías están cada vez más presentes en la vida cotidiana de las personas, lo que implica en un cambio en la velocidad de transmisión de la información, en la forma cómo se da la comunicación, la interacción entre las personas, y también en la formación de profesionales. En este escenario, tenemos los blogs, que son una especie de diario online utilizado para la comunicación y la interacción entre personas de diferentes edades, intereses y profesiones. A través de búsquedas en Internet, se constata que los blogs son ampliamente utilizados por los profesores. En esta perspectiva, este estudio tuvo como objetivo analizar y describir lo que los profesores dan a conocer en sus blogs en Educación Especial, y si estos contenidos están relacionados con la formación de estos profesionales. Para ello, se realizaron búsquedas en los sites utilizando el descriptor "educación especial". Como muestra, se seleccionaron diez páginas, tanto brasileñas como portuguesas. Se trazó un perfil del profesor que usa estos blogs y se analizo el contenido de los mensajes. Se puede concluir que estos profesores tienen, de alguna manera, relación con la Educación 
Especial. Los mensajes pueden ser clasificados en cuatro ejes y, tras el análisis, se constata que los blogs son espacios que contribuyen directamente a la formación de estos profesores.

Descriptores: Blogs, maestro de educación especial, formación del profesorado.

\section{Introdução e Revisão de literatura}

Atualmente, as tecnologias digitais, como softwares e ferramentas de internet, são cada vez mais presentes no cotidiano das pessoas. Em âmbito nacional, uma pesquisa realizada pela FecomércioR/Ipsos esclarece que o percentual de brasileiros conectados à internet teve um crescimento de $27 \%$ para 48\%, entre os anos de 2007 a 2011(1). De acordo com a pesquisa realizada e publicada pelo Grupo IBOPE (www.ibope.com.br), em abril de 2012, a expansão do número de brasileiros com acesso à banda larga é responsável por este aumento, já que 79,9 milhões têm acesso à internet.

Dessa forma, as Tecnologias Digitais da Informação e Comunicação (TDIC), que têm como objeto a informação, contribuem para o processo de fundamentação do conhecimento e, consequentemente, para a sociedade. Com o avanço das TDIC, qualquer informação pode ser inserida e difundida no ciberespaço, e acessada por qualquer pessoa que esteja conectada à internet(2). Sendo assim, pode-se dizer que com o advento da internet, a comunicação mudou, impactando nas mais diversas camadas da sociedade(3).

Da necessidade humana de interação, nascem os $b \log s$, sendo, então, essencialmente sociais(4). A palavra blog é uma contração da expressão weblog - web (do inglês, teia, também empregada para se referir ao ambiente virtual da internet) e log (do inglês, diário de bordo) - e, portanto, consiste em um tipo de página pessoal online, em que o conteúdo é disponibilizado em ordem cronológica. O conteúdo a ser disponibilizado fica a critério do autor, chamado "blogueiro", que pode postar textos, imagens e vídeos. As postagens são o espaço onde os mais variados gêneros circulam, e o foco dos blogs tem mudado, e atualmente se voltam para atividades profissionais e marketing pessoal(4).

Assim, os blogs não são mais tão parecidos com os diários, como eram há algum tempo. A possibilidade de agregar todo e qualquer gênero textual faz com que os blogs tenham características de sites pessoais, em que o responsável o alimenta com conteúdos a sua escolha(5).

Os blogs ainda são definidos como um fenômeno de massa que proporcionou uma significativa mudança na comunicação, uma vez que eles permitem que o cidadão se torne uma testemunha participativa, produzindo e distribuindo informação. Eles proporcionam interação e colaboração, pois 
viabilizam a divulgação de textos, artigos, imagens, emissão de opinião acerca de um assunto e, ainda, permitem que outros internautas comentem e opinem sobre o que está sendo veiculado(3).

No que diz respeito à educação, esta é influenciada diretamente pela internet e suas tecnologias. As novas tecnologias de comunicação proporcionaram novos espaços para o conhecimento, tanto de professores, quanto de alunos. Os blogs, por sua vez, favorecem a formação docente, já que são recursos ricos e interessantes, pois criam um ambiente propício a troca de ideias entre educadores(6).

As tecnologias começaram a ser utilizadas no século $\mathrm{XX}(7)$ e, mesmo recentes, influenciam na escola. No caso dos $b \log s$, eles têm servido como ferramenta no espaço acadêmico, pois são utilizados para mediar diálogos, entre alunos e professores(8).

Dessa forma, os processos educacionais devem ser repensados, considerando todos os envolvidos - alunos e professores.

\subsection{Blogs como espaço de formação de professores}

Os blogs, pela estrutura que oferecem, propiciam a criação de uma rede de colaboração com leitores e escritores, considerando os mais diversos pontos de vista e experiências(4). Dessa forma, podem ser utilizados por professores para uma formação reflexiva e colaborativa.

As novas tecnologias da informação, onde se inserem os blogs, são formas de conhecimento, uma vez que ao utilizá-las uma nova linguagem é criada, bem como novos conteúdos plásticos dos processos mentais. Além disso, uma rede de computadores pode impactar no modo de pensar de professores e alunos, permitindo assim uma formação de professores e um novo paradigma educativo(9).

Machado(6) mostra, em sua pesquisa, a preocupação dos professores na utilização dos computadores, internet e seus recursos, pois permitem que os muros da escola sejam quebrados e conteúdos significativos ensinados aos alunos. No blog criado pelo pesquisador, com o intuito de verificar a formação de professores, constatou-se que neste ambiente, os docentes puderam ler diversos textos, refletir, criticar e interagir com outros professores de outras redes, o que contribuiu para ampliar o repertório daqueles professores que interagiram por meio do blog.

Em consonância com essa ideia, a formação não deve necessariamente se realizar no espaço físico da escola, mas sim que as necessidades da formação surjam do contexto educacional em que se 
busca desenvolver o educador como um crítico da tecnologia, que a utiliza em sua prática pedagógica, promovendo mudanças, sejam elas em sua própria atuação, ou no contexto em que está inserido(10).

\section{Objetivos}

Este trabalho teve como objetivos analisar e descrever o que professores divulgam em seus blogs sobre a Educação Especial, e se tais conteúdos se relacionam à formação destes profissionais.

\section{Método}

Para atingir os objetivos deste trabalho, foi realizada uma pesquisa documental, a partir de um levantamento feito no site de buscas Google (www.google.com), com filtro "Pesquisa de Blogs" ativado. Foi utilizado o descritor "educação especial", que gerou um resultado de aproximadamente 310.000 páginas. Mesmo realizando a pesquisa com este filtro, o site de buscas reconhece algumas páginas de sites de empresas, escolas e diretorias de ensino como blogs, sendo então necessário acessar as páginas para verificar quais delas realmente são um diário online.

A amostra foi delimitada no total de dez blogs, tanto brasileiros, quanto portugueses, já que estes últimos também constavam no resultado obtido a partir da busca preliminar. Com o intuito de selecionar os dez blogs, alguns critérios de inclusão e exclusão foram estabelecidos. Páginas constantemente atualizadas e com postagens recentes, cujos autores são professores e tenham algum envolvimento com a educação especial, como professores de sala comum, professores de sala de recursos e professores pesquisadores, foram incluídas. Descartaram-se aquelas cujos autores eram identificados como secretarias de municípios, diretorias de ensino e escolas; e blogs cuja temática não é a educação especial. Aqueles que tinham como eixo norteador a educação especial, mas com postagens que não se referiam à área também não foram levados em consideração. Dessa forma, foram elencados os dez primeiros blogs que atenderam aos critérios acima estabelecidos.

Os blogs selecionados foram analisados e as informações obtidas foram sistematizadas em uma tabela. Os elementos examinados foram: (a) o perfil do(s) blogueiro(s) e sua relação com a educação especial; e, (b) o conteúdo que é veiculado (se são textos escritos pelo próprio autor ou textos copiados e colados de outras fontes). No item (b), também foi analisado se o que é disponibilizado tem ou não relação com a formação destes profissionais. 


\section{Resultados e discussão}

A partir dos dez blogs elencados, foi analisado e descrito o que, e também de que forma, é disseminado na rede acerca da Educação Especial, e qual o perfil do professor-blogueiro.

\subsection{Perfil do blogueiro e sua relação com a educação especial}

Os blogs são uma espécie de diário virtual, uma página na internet em que o autor tem a liberdade de publicar qualquer tipo de texto(3). Sendo assim, qualquer pessoa com acesso à internet e que tenha noções de informática pode criar um blog, normalmente para compartilhar algo de seu interesse.

Ao criar um blog, o responsável por ele tem a opção de preencher um perfil, com profissão, local, interesses e o motivo que o levou à produção do seu diário online. Dentre os blogs selecionados, apenas uma das autoras não preencheu completamente o perfil. Um dos blogs também conta com a colaboração de outras duas pessoas com deficiência, porém a grande maioria das postagens é feita pela professora, a qual se diz responsável pelo blog.

Esse grande grupo de professores-blogueiros foi desmembrado em subcategorias, a fim de se ter mais detalhes acerca do perfil dos autores. Essas subcategorias foram listadas de acordo com o que se declaram os autores dos blogs. São elas: professor de sala de recursos; professor especialista em alguma deficiência; professor coordenador de Educação Especial de determinada Secretaria Municipal; professor de Educação Especial; professor auxiliar de alunos com deficiência na sala comum; professor especialista em Educação Especial; e professor universitário. Vale ressaltar que um mesmo blogueiro pode fazer parte de mais de uma subcategoria. Os dados obtidos foram sistematizados na Tabela 1, de acordo com a categoria a que pertence e quantidade encontrada na amostra.

\begin{tabular}{|c|c|}
\hline CATEGORIA & $\begin{array}{c}\text { QUANTIDADE } \\
\text { ENCONTRADA NA } \\
\text { AMOSTRA }\end{array}$ \\
\hline Professora de sala de recursos & 03 \\
\hline Professor especialista em alguma deficiência & 02 \\
\hline Professor coordenador de Educação Especial de Secretaria \\
Municipal
\end{tabular}




\begin{tabular}{|c|c|}
\hline Professor de educação especial & 03 \\
\hline Professor auxiliar do aluno com deficiência em sala comum & 01 \\
\hline Especialista em Educação Especial & 04 \\
\hline Professor universitário & 01 \\
\hline
\end{tabular}

Tabela 1 - Perfil do blogueiro

Assim, pode-se concluir que todos os professores-blogueiros possuem relação com a Educação Especial em seu ambiente de trabalho. Um dos autores declara ter familiar com deficiência.

O perfil dos professores blogueiros da educação especial, tanto brasileiros quanto portugueses, são profissionais que, de alguma forma, se relacionam diretamente com a educação especial, seja como professor de sala de recursos, especialistas que trabalham com pessoas com deficiência, coordenadores da área de educação especial e professores que têm alunos com deficiência, nos mais diversos níveis de ensino - fundamental, médio e superior. Porém, nota-se que o perfil predominante é de professores de sala de recursos, da educação especial e que tem uma especialização na área.

Além disso, nota-se que apenas um dos blogs analisados pertence a um professor do sexo masculino. Todos os outros são de professoras.

\subsection{Conteúdo}

Os conteúdos dos blogs analisados estão em consonância com os objetivos estabelecidos pelos professores-blogueiros, na página inicial dos blogs. Assim, se um professor-blogueiro se dispôs a postar textos que se referem às questões da Educação Especial, e propor reflexões acerca do tema, nota-se que as postagens não se desviam do eixo norteador.

Para descrever e analisar o que os professores blogueiros divulgam na rede mundial de computadores, todas as postagens foram analisadas, desde o início do blog até as mais recentes. É interessante ressaltar que quase a metade das páginas analisadas foi criada no ano de 2012. Dos dez blogs selecionados para amostra, quatro iniciaram em 2012, um no ano de 2011, dois em 2009 e 2010, e um no ano de 2007. Alguns deles foram inicialmente elaborados como um dos requisitos para conclusão de curso de formação continuada na área da educação especial, porém, os autores decidiram 
continuar alimentando o blog.

Os dados obtidos a partir da análise das postagens foram registrados em na tabela abaixo (Tabela 2). Cada um dos blogs recebeu um número de identificação para facilitar a sistematização dos dados. Vale ressaltar que os blogs número 9 e 10 são portugueses e os outros, brasileiros.

\begin{tabular}{|c|c|}
\hline$B L O G$ & CONTEÚDO DAS POSTAGENS \\
\hline 1 & $\begin{array}{l}\text { Divulgação de curso ofertado pela professora-blogueira; estratégias e sugestões de trabalho } \\
\text { pedagógico; relatos de experiência pedagógica; cursos de formação continuada oferecidos pela } \\
\text { escola; opinião; reportagens; informações sobre deficiências; eventos realizados pela escola, } \\
\text { envolvendo os alunos com necessidades educacionais especiais; vídeos de reportagens; trechos } \\
\text { da legislação; artigos escritos pela professora blogueira; fotos da escola onde trabalha, } \\
\text { mostrando seu trabalho; textos para reflexão. }\end{array}$ \\
\hline 2 & $\begin{array}{l}\text { Divulgação da prática docente da professora blogueira, bem como reflexões; vídeos; textos } \\
\text { escritos pela professora blogueira; reportagens; artigo cientifico publicado pela professora } \\
\text { blogueira. }\end{array}$ \\
\hline 3 & $\begin{array}{l}\text { Relato de participação em curso de formação continuada ofertado pela escola em que trabalha; } \\
\text { divulgação de eventos; relato de experiência pedagógica; relato de palestras e cursos que a } \\
\text { professora blogueira participou; vídeos. }\end{array}$ \\
\hline 4 & $\begin{array}{l}\text { Divulgação de recursos para serem utilizados com alunos com necessidades educacionais } \\
\text { especiais; textos relacionados à aprendizagem e deficiências; relato de experiências } \\
\text { pedagógicas; divulgação de trabalho de conclusão de curso realizado pela professora blogueira; } \\
\text { textos para reflexão (de autoria da professora blogueira e retirados de outras fontes); evento } \\
\text { realizado pela professora blogueira; indicações de sites. }\end{array}$ \\
\hline 5 & $\begin{array}{l}\text { Reportagens; informações sobre deficiências; divulgação de congressos, seminários, oficinas e } \\
\text { cursos na área; reflexões da professora blogueira. }\end{array}$ \\
\hline 6 & $\begin{array}{l}\text { Divulgação de curso online ofertado pela professora blogueira; divulgação de cursos e } \\
\text { congressos; entrevistas (retiradas de outras fontes); vídeos; textos escritos pela professora } \\
\text { blogueira; relato e reflexão de sua prática pedagógica. }\end{array}$ \\
\hline 7 & $\begin{array}{l}\text { Divulgação de cursos relacionados a LIBRAS; divulgação de cursos, congressos e seminários; } \\
\text { divulgação de escolas públicas para deficientes auditivos; indicações de livros e sites; indicação } \\
\text { de locais públicos acessíveis, como teatros e bibliotecas; reportagens; vídeos; legislação. }\end{array}$ \\
\hline 8 & $\begin{array}{l}\text { Reportagens; vídeos; entrevistas; ilustrações; informações sobre deficiências; reflexões da } \\
\text { professora blogueira; indicações de filmes e livros; indicações de locais públicos acessíveis, } \\
\text { como bares e casas noturnas; divulgação de eventos que envolvem pessoas com deficiência; }\end{array}$ \\
\hline
\end{tabular}




\begin{tabular}{|c|l|}
\hline 9 & divulgação de cursos. \\
\hline 9 & $\begin{array}{l}\text { Reportagens; divulgação de cursos oferecidos; ilustrações; cursos de formação continuada } \\
\text { oferecidos pela escola; divulgação de eventos; eventos realizados pela escola; vídeos } \\
\text { (reportagens); textos para reflexão; estratégias/ sugestões de trabalho pedagógico; informações } \\
\text { sobre deficiências. }\end{array}$ \\
\hline 10 & $\begin{array}{l}\text { Muitos textos para reflexão e discussão (retirados de outras fontes); reportagens; legislação } \\
\text { portuguesa; divulgação de cursos; vídeos; divulgação de tecnologias para serem utilizadas com } \\
\text { pessoas com necessidades especiais, tanto na escola, quanto fora dela; relato de experiência } \\
\text { pedagógica; divulgação de provas em âmbito nacional; opiniões e reflexões do professor- } \\
\text { blogueiro acerca de reportagens e vídeos; textos escritos pelo próprio professor-blogueiro. }\end{array}$ \\
\hline
\end{tabular}

\section{Tabela 2 - Conteúdos das postagens}

Dessa forma, embora os objetivos e público-alvo dos blogs sejam diferentes, o conteúdo das postagens dentre os blogs, tanto brasileiros quanto portugueses, são similares, como registrado na tabela acima.

As postagens podem ser categorizadas nos seguintes eixos: (a) textos escritos pelo próprio professor-blogueiro; (b) textos retirados de outras fontes; (c) vídeos; (d) divulgação de cursos, palestras, congressos, seminários e oficinas na área da Educação Especial.

Ao analisar os textos escritos pelo próprio professor-blogueiro, percebe-se que esses textos podem ser opinativos, em que o professor discute um tema, uma reportagem, ou ainda, exprime sua opinião acerca da educação e da escola onde trabalha; relatos de experiência, da prática docente, ou a respeito de formações em que participou, tanto como ouvinte, como palestrante; e recursos pedagógicos, desenvolvidos pelo professor-blogueiro para utilização em sala de aula. Nota-se também a preocupação de alguns professores blogueiros com sua formação, pois alguns deles publicam seus próprios artigos científicos, ou ainda, resultados de pesquisas desenvolvidas. No segundo e terceiro tipos de postagem, é comum que os textos sejam acompanhados de fotos, seja do local em que se deu a experiência, ou do material criado pelo professor.

Cabe ressaltar que a presença deste tipo de postagem é muito maior nos blogs brasileiros. As postagens mais comuns nos blogs de portugueses são textos de outros autores.

Os textos retirados de outras fontes versam em reportagens e entrevistas, retiradas de revistas online, sites e outros blogs, sendo todas elas relacionadas à educação especial. Também podem ser encaixados neste item alguns dos recursos pedagógicos disponibilizados nos diários virtuais, já que 
muitos deles são retirados de outros blogs, ou de outros sites. É comum também os professores divulgarem trechos da legislação vigente, bem como novos decretos.

Os vídeos, em sua grande maioria, também são retirados de outras fontes. São entrevistas, reportagens e depoimentos de pessoas com deficiência. Apenas um destes vídeos, postado em um blog português, mostra a prática pedagógica do professor, em que seus alunos cantam uma música sobre a inclusão escolar.

Os professores-blogueiros também divulgam eventos, palestras e cursos, que são destinados tanto à formação continuada quanto para lazer, como grupos de dança formados por pessoas com deficiências. Porém, a grande maioria das postagens é de divulgação de eventos e cursos, todos relacionados à área da educação especial e voltados para a formação de professores. Alguns dos cursos foram elaborados e desenvolvidos pelos próprios professores blogueiros, sendo alguns deles a distância e outros presenciais.

\section{Conclusão}

Os blogs podem ser utilizados como ambiente de formação de professores, que atuam nas mais diversas áreas, como na Educação Especial, recorte deste trabalho.

A partir das buscas realizadas para a seleção preliminar, pode-se constatar que muitos professores têm utilizado blogs para expor sua prática pedagógica, compartilhar ideias e trocar experiências, o que leva a reflexões que impactam na sua formação profissional e, consequentemente, na prática pedagógica destes profissionais.

A partir da amostra selecionada, conclui-se que o professor envolvido com a Educação Especial tem essa preocupação, uma vez que têm relação direta com a área. Além disso, observa-se que a maioria faz cursos na área, de capacitação e especialização. Alguns, inclusive, contribuem para a formação de outros professores, por meio dos cursos ofertados.

Após análise dos blogs, pode-se dizer que seguem determinado padrão quanto às postagens, em que textos ora são de própria autoria do professor-blogueiro, ora de outras fontes. Também disponibilizam vídeos e cursos na área. Percebe-se assim que há uma preocupação do professorblogueiro com a área em questão, pois além de se posicionarem acerca de um tema, o conteúdo divulgado é informativo, contribuindo assim, para a ampliação do repertório dos seus leitores, uma vez 
que, ao se observar os comentários, percebe-se que muitos deles também se posicionam, emitindo opinião acerca do que foi publicado.

Sendo assim, os blogs podem ser uma opção para comunicação, formação e informação, principalmente, entre professores, e também outros profissionais e o público-alvo leitor da página. Os blogs, assim, servem como espaço de formação informal para estes professores, já que a disponibilização de informações exige leituras, buscas, mesmo que não seja um texto de autoria do professor-blogueiro. Os comentários, típicos deste tipo de página, também são um ponto que viabilizam a reflexão dos professores acerca do que foi postado, já que o internauta pode se posicionar a favor ou contra a publicação, ou ainda postar outras considerações acerca do assunto. Além disso, os comentários proporcionam interação com outros profissionais da área, ou leitores a que o blog se destina.

\section{Referências Bibliográficas}

1. ALMEIDA, F.J. O educador, magnamidades e ambiguidades. São Paulo em Perspectiva [periódico na Internet]. 2001 [citado 2012 ago. 09]; 15(2). Disponível em: http://www.scielo.br/scielo.php?pid=S0102-88392001000200013\&script=sci_arttext\&tlng.

2. ALMEIDA, M.E.B. Formação de professores para inserção do computador na escola: interrelações entre percepções evidenciadas pelo uso do software CHIC. Revista Educação Matemática Pesquisa [periódico na Internet]. 2002 [citado 2012 ago. 09]; 4(2). Disponível em: http://math.unipa.it/ grim/asi/asi_03_bianconcini.pdf.

3. ANTONIOLI, L. Estatísticas, dados e projeções atuais sobre a Internet no Brasil. 2012 [citado em 2012 ago. 08]. Disponível em: http://www.tobeguarany.com/internet_no_brasil.php..

4. BARDY, L.R. Objetos de aprendizagem em contextos inclusivos: subsídios para formação de professores [dissertação]. São Carlos: Programa de Pós-Graduação em Educação Especial, Universidade Federal de São Carlos, São Carlos; 2010.

5. BRESOLIN, A.R. O professor de línguas em formação: uma experiência reflexiva com blog [dissertação]. Cuiabá: Programa de Pós-Graduação em Estudos da Linguagem, Universidade Federal do Mato Grosso; 2011.

6. LOPES, L.R. O blogueiro e suas práticas - corpos carnavalizados e interações multifacetadas 
[dissertação]. São Carlos: Programa de Pós-Graduação em Linguística, Universidade Federal de São Carlos; 2010.

7. MACHADO, J.L.A. Escolhendo a pílula vermelha: Blogs na formação de professores [tese]. São Paulo: Programa de Pós-Graduação em Educação, Pontifícia Universidade Católica; 2008.

8. PIMENTA, S.A.; PETRUCCI, M.R. Ambientes virtuais para a cultura como educação: aproximações conceituais e metodológicas. Informação e sociedade: Estudos. 2010; 20(2).

9. $\quad$ PRIMO A.; SMANIOTTO A.M.R. Comunidades de blogs e espaços conversacionais. Revista Prisma.com [periódico na Internet]. 2006 [citado 2012 ago. 09]; 3:1-15. Disponível em: http://www6.ufrgs.br/limc/PDFs/insanus.pdf.

10. SILVA, F.M. O leitor de blog: um estudo com base nos blogs mais acessados do Brasil [tese]. Araraquara: Programa de Pós-Graduação em Linguística e Língua Portuguesa, Universidade Estadual Paulista; 2009. 